\title{
Qualidade de vida e meio urbano. A cidade de São Paulo, Brasil ${ }^{*}$ Quality of life in an urban environment. S. Paulo city, Brazil
}

\author{
Oswaldo Paulo Forattini** \\ FORATTINI, O.P. Qualidade de vida e meio urbano. A cidade de São Paulo, Brasil. Rev. Saúde públ., \\ São Paulo, 25: 75-86, 1991. Apresenta-se a conceituação de qualiclade de vida, considerando-se a \\ possibilidade de sua avaliação. Assinalam-se-lhe as feições gerais, de caráter individual e coletivo, \\ acompanhadas dos aspectos principais relativos aos possíveis determinantes. Focaliza-se a cidade de \\ São Paulo, Brasil, no que conceme aos aspectos coletivos $\mathrm{c}$ individuais da qualidade de vida de seus \\ habitantes.
}

Descritores: Qualidade de vida. População urbana.

\section{Introdução}

Em sua tão conhecida conceituação de "saúde", a Organização Mundial da Saúde (OMS), a certa altura emprega a expressão "bcm-estar físico, mental e social". Como se depreende facilmente, isso deu origem a discordâncias de interpretaçĩo que, de maneira geral, oscila entre a que accita o modelo darwiniano na antropologia, e aquela que advoga a necessidade de adequá-la à condição humana. São portanto dois pontos de vista cxtremos, dentre os quais certamente se silua a verdade, esta representada pelo papel decisivo desempenhado pela adaptação e evolução cultural. Se, cm qualquer tempo, for considerada a população, nota-se que ela participa de conjunto de estralégias adaptativas inter-relacionadas, elaboradas por indivíduos e comunidades, e objelivando enfrentar situações presentes e futuras. Daí o envolver do planejamento, com a finalidade de determinar o tipo de participação humana, e entendendo-se, assim, a sobrevinda de condições favoráveis a crros $\mathrm{c}$ manipulações. Consęüentemente, é de se admitir que, qualquer que scja o momento, a siluação que se apresenta constitui estado dinâmico onde são alssumidos compromissos entre individuos ou grupos e os objctos planejados para as chapas fuluras. Entre estes, inclui-se fundamentalmente a quali-

\footnotetext{
* Publicação financiada pela FAPLSP.

* Departamento de Epidemiologia da Faculdade de Saúde Pública da Universidade de São Paulo - Sĩo Paulo, Sl’ Brasil.

Separatas/Reprints: O.P. Forattini Av. Dr. Arnaldo, 715 01255 - São Paulo - Brasil.
}

dade de vida; a qual, em sua essência, pode ser traduzida pela satisfação em viver.

\section{Conceituação}

É de se entender com facilidade os obstículos que se apresentam para se alcançar conceituação precisa do que vem a ser qualidade de vida. O seu caráter subjetivo, $\mathrm{cm}$ especial modo $\mathrm{cm}$ nível individual, constitui parte que lhe e praticamente inerente, motivo pelo qual não deixa de exercer a sua influência. Para alguns, a qualidade de vida seria a somatória de fatores decorrentes da interação entre sociedade $c$ ambiente, atingindo a vida no que concerne às suas necessidades biológicas e psíquicas (Coimbra ${ }^{3}$, 1985). Tal orientação, no sentido de priorizar as necessidades, $t \mathrm{~cm}$ sido geralmente aceita, reconhecendo-se assim certo número delas. No cstado atual da sociedade, formam trama cada vez mais complexa, ao longo da qual se desenrola a vida humana. Considerando-se as que são inerentes c as que são adduiridas, pode-se verificar a sua distribuição pelas dilerentes áreas, lísica, psicológica, social, de atuação, matcrial e estrutural. Dessa maneira, a qualidade de vida é delinida como sendo o grau de satisfação atingido, no âmbito de tais áreats (Hörnquist ${ }^{8}$, 1982). Gencricamente, reconhecemse dois lipos de necessidades especificas, as concretas $\mathrm{c}$ as abstratas. Aquelas são de caráter geral, como alimentação e a moradia. As abstratas revestem-se de aspecto mais particular, como a autoestima. Scja como for, há de se dizer que a conceituação da qualidade de vida ainda não logrou aceitação universal. Argumenta-se que cssa expressão presta-se a ser utilizada para conceito muito poli-

11) Série comemorativa do $25^{\circ}$ aniversário da Revista de Saúde pública. 
morfo, incluindo necessidades extremamente heterogêneas, e ao sabor das opiniōes dos värios autores (Dam e col. ${ }^{4}, 1981$ ).

Sob o ponto de vista da saúde e diante do estado atual da questão, há de se convir em duas maneiras essenciais de encará-la, a individual e a coletiva. A primeira, destina-se aos casos que, ao serem afctados pelo agravo, sofrem conseqüente decréscimo de sua capacidade funcional. A segunda refcre-se ao resultado da presença e atuação de determinantes da doença e comprometimentos da saúde, tanto da natureza física, como biológica $\mathrm{c}$ social.

\section{Avaliação}

Às dificuldades de conceituar a qualidade de vida somam-se as referentes às possibilidades de sua mensuração. Sob o ponto de vista assistencial, o dcsenvolvimento tecnológico da prática médica propiciou a análise do bem-estar de pessoas doentes ou idosas, a guisa de complementação dos estudos de morbidade e de mortalidade. De forma geral, daí têm resultado medidas que podem ser consideradas como objetivas e subjetivas. É fácil de deprecnder que as primeiras se fundamentam $\mathrm{cm}$ indicadores concretos, a exemplo da Laxa de descmprego e a densidade habitacional. Quanto às subjetivas, decorrem do uso de indicadores abstratos, baseados $\mathrm{cm}$ informações colhidas diretamente dos indivíduos que compõem a população em estudo. Obviamente, qualquer desses procedimentos, tomado isoladamente, não poderá fornccer estimativa satisfatória do grau da qualidade de vida de determinada comunidade.

O estado de satisfação ou de insatisfação constitui, na verdade, experiência de caráler pessoal. Tal aspecto intrínseco projeta-se extrinsecamente no propósito de obtenção de melhores condiçōes de vida. Assim sendo, o grau de ajustamento às situações existentes, ou então, o desejo de mudança, poderá servir para avaliar a presença ou ausência de satisfação. Dessa mancira, partindo-se da premissa de que é a opinião do indivíduo que identifica a ação de fatores determinantes da qualidade de sua vida, estes têm sido agrupados como seguc (Hörnquist ${ }^{9}, 1990$ ):

1 -orgânicos: saúde e estado funcional.

2 -psicológicos: identidade, auto-cstima, aprendizado.

3 - sociais: relacionamento, privacidade, sexualidade.

4 - comportamentais: hábitos, vida prolïssional, lazer.

5 - materiais: economia privada, renda, habitação.

6 - estruturais: posição social, significado da própria vida.
Assim procedendo, tal avaliação tem sido aplicada em indivíduos portadores de doenças e agravos diversos, além de idosos e os sujeitos a vícios como os de dependêcia a drogas. Em muitos casos pôde-se observar efeitos benćficos sobre os estados depressivos que afetam essas pessoas.

Em que se pese o aspecto individual acabar se refletindo no colclivo, é óbvio que a qualidade de vida da população, como um todo, somente poderá ser avaliada mediante o uso de indicadores concretos. Nesse particular, poderá ocorrer discordância em relação aos resultados obtidos com os abstratos. No entanto, é a estrutura social, em seu sistema de classes, que detcrmina a qualidade de vida coletiva, como resultante das condições do meio que se desenvolvem nessa sociedade. Essa concepção social da qualidade de vida, data já de algum tempo, motivo pclo qual são bastante numerosos os indicadores destinados à sua avaliação. De maneira ampla, é possível agrupá-los em relação aos vários aspectos, como segue (Papagcorgiou ${ }^{14}, 1976$ ):

1 - ambientais: qualidade da água, do ar e do solo, domesticação c domiciliação, acidentalidade.

2 - habitacionais: disponibilidade espacial e condições de habitabilidade.

3 - urbanos: concentração populacional, comunicaçãa, transporle, scgurança, poluição.

4 - sanitários: assistência médica, morbidade, mortalidade.

5 - sociais: sistemas de classes, nivel socioeconômico, consumo, necessidades, sexualidade, condições de trabalho, lazer, sistema políticoadministralivo.

Todos esses aspectos, além de vários outros, têm sido utilizados na claboração de indicadores objetivando delerminação quantitativa. Todavia, como incvitavelmentc ocorre, eles se interrelacionam intimamente, $\mathrm{e}$ tal sistcmatização por categorias definidas, torna-se bastante discutivel. Diante disso, preferc-se adotar orientação geral que consiste cm considerá-los, conjuntamente, como de carálter social.

Embora as medidas utilizadas na avaliação da qualidade de vida coletiva tendam ao uso de indicadores concrelos, a questão torna-se particularmente complexa quando se objetiva avaliar determinadas situaçōes e comportainentos. Em decorrência, as soluções postas em prática para elevaro nível da qualidade de vida populacional são geralmente parciais, embora se fundamentem $\mathrm{cm}$ indicadores cspecílicos para cada caso.

\section{O Ambiente Urbano}

A cidade constitui ccossistema antrópico, onde o grau de artificialidade atinge scu nível mais clevado. 
Atualmente presencia-se o efeito do processo de urbanização, em cada vez maior número de núclcos, chegando a praticamente desvincular o ser humano de seu relacionamento com a natureza. Daí decorrem aspectos particularmente intensos e concrentrados em áreas relativamente limitadas. As conseqüências fazem-se sentir a distâncias às vezes consideráveis. $E$ isso em virtude da nccessidade de entrada maciça de energia para a zona urbana. Além da representada pelos alimentos, sobressacm a dos combustíveis e da cletricidadc. Captadas $\mathrm{cm}$ locais distantes, são transformadas, concentradas c, quando possivvel, armazenadas para ulterior utilização. Como consequiência, dá-se intensa produção de resíduos que representam a reversão ao estado não concentrado, e que são constituídos principalmente pelos dejectos e pelo calor.

É de se considerar, pois, que o desenvolvimento do meio urbano resulta em intensa e profunda manipulação do ambiente. Daí decorrerem acentuadas modificacões que recacm sobre a paisagem, a comunidade, o estado psicológico e fisiológico dos habitantes, além de darem origem a fatores culturais, tanto econômicos como políticos que, isolada ou coletivamente, influem ou mesmo detcrminam a qualidade de vida da população ali residente. Assim sendo, pode-se enumerar, de maneira genérica, as características do ambiente urbano, como scguc:

1 - afastamento e ausência de contato com o meio natural.

2 - concentração e elevada densidade populacional, em espaço limitado.

3 - predominância de alividade industrial e de prestação de scrviço.

Como já foi mencionado, os indicadores relativos ao ambiente urbano, têm sido usados $\mathrm{cm}$ scu carătcr concreto. Assim procedendo, tem-se avaliado os aspectos concernentes à morbidade, mortalidade, esperança de vida ao nascer e muitos outros. Nessa ordem de idćias, a qualidade de vida coleliva é encarada como representando ou não, problema social. E isso desde que ela, respectivamente, atinja ou não, nível considerado insalisfatório, de acordo com esses indicadores. No caso de se crigir cm problema, é certo que sua solução independerá da aluação dos indivíduos, tomados isoladamente, mas sim dependerá do comportamento da população, estruturada $\mathrm{cm}$ sociedade. Esta, colocada frente à problemática, adotará atilude que poderá scr de aceitação, de convivência ou de tentativa de solução. Assim sendo, há que se considerar de que forma os fatores, anteriormente citados, atuam no modo e na salisfação de viver, em outras palavras, no bem-estar dos habitantes da cidade.

Desde o término da Segunda Gucrra Mundial, assiste-se o acentuado incremento do fenômeno da urbanização, para o qual os autores têm aventado múltiplas explicações. À clássica teoria do desenvolvimento industrial que $\mathrm{fcz}$ crescer as cidades, acrescenta-se o da mecanização agrícola que leva, como decorrência, a mão de obra a se concentrar no meio urbano. Qucm, por que, e como, se engaja na migração rural-urbana, são questões que se filiam a aspectos da estrutura social e das condições sócioeconômicas, ou scja, do sistema de distribuição da riqueza. Para alguns, pode-se distinguir os migrantes voluntários, daçueles que não têm outra alternativa para a sobrevivência (Du Toit $\left.{ }^{5}, 1990\right)$. Seja como for, tal tendência tcm levado, pcla sua feição desordenada, à exacerbação dos aspectos urbanos, consubstanciada na concentração, comunicação, transporle, segurança e poluição. Em conseqüência, passam a influir intensamente na qualidade de vida da população, recaindo sobre os já citados determinantes que compremetem a salisfação de viver, tanto no lerreno individual como coletivo.

Em artigo como este, dificilmente se conseguirá abordagem, global e detalhada, de todos os aspectos atualmente envolvidos na determinação da qualidade de vida urbana. Embora a socicdade, como fenômeno ecológico que ć, não seja feição privativa da espécie humana, é-lhe peculiar a extrema complexidade que atingiu e não cessa de crescer. Dcixando de lado o inevitável inter-relacionamento dos múltiplos fatores, talvez possa se considerar a preeminência dos mencionados no parágrafo anterior, na caractcrização da vida nas cidades.

\section{A Cidade de São Paulo}

No Brasil, a evolução urbana, desde o periodo colonial, tem sido objelo de numcrosos estudos e publicações. Em nosso país, esse processo de formação das cidades iniciou-se como necessidade de estabclecer núcleos de colonização estáveis e de dcfesa militar para, postcriormente e com o advento já tardio da cra industrial, passar a refletir o desenvolvimento econômico conseqüente. Isso foi particularmente significante no caso do Estado de São Paulo, cuja Capital, após as primeiras décadas deste século, teve scu intenso crescimento como tradução desse desenvolvimento da economia local (Reis Filho ${ }^{15}, 1968$; Singer ${ }^{21}$, 1968; Righi ${ }^{16}, 1983$ ). Assim, de mancira geral, a condição de país, basicamente urbano, foi atingida pelo Brasil, no curto espaço de tempo correspondente ao período de 1940 a 1970.

Antes dessa ćpoca, o país ainda era essencialmente rural, uma vez que, em 1940, viviam no campo $69,0 \%$ de sua população. Na década dos anos 60, a cvolução do caráter eminentemente urbano de São Paulo corre paralclamente ao decréscimo do contingente rural, evidenciando o progredir da urbanização da população regional. 
Nesse período, o surto industrial da cidade de São Paulo cresce intensamente, alicerçado em infraestruturas originadas de décadas anteriores, quando da expansão da economia cafecira (Ronca ${ }^{19}$, 1983). Chega-se assim ao final dos anos $80 \mathrm{com}$ essa cidade transformada em metrópole ou megalópole, na qual as conseqüências para a qualidade de vida de seus habitantes resultam dessa evolução sem qualquer planejamento prévio e adequado, ao menos na proporção que scria de se descjar.

\section{Aspectos Coletivos}

Em publicação recente, a Prefeitura de São Paulo divulgou informações visando possívcl adequamento futuro da vida nessa cidade (Rolnik e col. ${ }^{18}$ 1990). Podem ser ali encontrados os principais dados referentes ao perfil demográfico, à distribuição de renda, ao uso do espaço e outros aspectos que, no dizer desse documento, transformaram São Paulo na "cidade do subdesenvolvimento industrializado". Grande parte dos dados apresentados a seguir, tem essa origem.

A região correspondente à chamada Grande São Paulo, conta atualmente com população da ordem de 17,4 milhões de habitantes, com crescimento vegetativo influcnciado pelo aumento da esperança de vida ao nascer e conseqüente envelhecimento populacional. Tal crescimento não é uniforme, mas sim destaca-se em determinadas áreas ("anéis") c na década dos anos 80 verificou-se ccrto cquilíbrio entre o decenal vegelativo $(16,33 \%)$ c o rclativo ao migratório $(17,16 \%)$ no mesmo período. Conludo, esse rápido crescimento, levando à expansão da árca urbana, não se fez acompanhar, na mcsma mcdida, por adequada ampliação de infra-cstrutura básica, como sancamento e transporte. Em decorrência, vcrificou-se progressiva deterioração da qualidade de vida, cuja direção assumiu aspecto centrípcto, isto é, caminhando da periferia para a zona central. É verdade que, a partir dos anos 70 , pôde-se observar cxpansão apreciável do abastecimento de água, da assistência médica e da cobcrtura vacinal relativa a determinadas infecções. Isso resultou no aumento da esperança de vida, com a mortalidade infantil descendo para estimativa de $35,1 \%$ por ocasião do fím da década de 80. Contudo, nesse mesmo período observou-se a ocorrência de aumentos localizados desse coeficiente, cm relação a certos bairros, c atribuidos a doenças pulmonares em menores de um ano de vida, sugerindo piora das condiçōes habitacionais (Baldijão apud Rolnik e col. ${ }^{18}, 1990$ ). Esse fenômeno foi associado à proliferação de cortiços, ou seja, ocupação de cdilícios residenciais deteriorados "a posteriori". Considerando-se, na região metropolitana de São Paulo em 1985, o número de pessoas pobres e não-pobres que não dis- punham de abastecimento de água potável e nem de sistema de csgotos domésticos, pôde-sc obter o que segue (Rocha $\left.{ }^{17}, 1990\right)$ :

$\begin{array}{lcc} & \text { sem água } & \text { sem esgotos } \\ \text { Pobres } & 935.188 & 1.916 .783 \\ \text { Não-pobres } & 267.722 & 969.430 \\ \text { Total } & 1.202 .910 & 2.856 .613\end{array}$

o que resultou, para aquele ano, em mais de 4 milhōes de habitantes desprovidos desses scrviços básicos.

O percentual correspondente a famílias pobres chegou a 42,1 cm 1987 (Lopes e Gottschalk ${ }^{12}$, 1990). No final da década de 80 e a início da de 90 ainda não existem evidências que permitam supor alteração significativa desse quadro. É de se admitir pois que, como $\mathrm{cm}$ anos anteriores, $\mathrm{cm}$ São Paulo o custo de vida para os pobres continua sendo o mais elevado do país, devido especialmente aos gastos com a alimentação (Rocha $\left.{ }^{17}, 1990\right)$. Assim pois, tal situação traduz nível acentuado de desigualdade social e de modificação na tendência da distribuição espacial por parle da população de baixa renda. Nestes últimos dez anos, $\mathrm{cm}$ vários bairros ou subdistritos, verificou-sc tendência ao aumento na participação das camadas de menor renda, chegando alguns a acolherem até $60,0 \%$ de pobres cntre scus habilantes. Assim, em 1977 existiam 34 áreas com predominância de população de baixa renda, mas predominantemente situadas nos limites do município. Decorridos dez anos, e portanto em 1987, embora tenham se reduzido a 25 , e ainda na periferia, notou-se scu aparecimento em áreas mais centrais, através da proliferação de cortiços. Essa diminuição não traduz melhoria do quadro da desigualdade, uma vez que se verificou mul liplicação de bairros onde se mesclam camadas pobres c intermediárias. Oque, na verdade, aconteceu, foi a redução dos niveis de renda familiar, alingindo também as camadas de padrão médio. Em decorrência desse achatamento nos níveis de remuncração, os vários estratos se aproximaram em várias regiões da cidade. Em outras palavras, muitos pobres abandonaram suas moradias na perifcria $\mathrm{e}$ passaram a ocupar cortiços no centro da cidade. Por sua ve de se deslociar de suas residências centrais, e passar a morar $\mathrm{cm}$ zonas mais perifóricas. A esse fenômeno, a já cilada publicação ${ }^{17}$ denomina de "diminuição perversa da segregação sócio-espacial". Como resultado linal, deu-se a pauperização, atingindo a maioria dos habitantes de São Paulo.

Há que se considerar que a pobreza não se limila à insuficiêencia da renda, mas sim constitui condição ou síndrome que se relaciona a vários tipos de carência. Entre esles, cstão aqueles que se referem à participação do poder público no assim chamado salário indireto, isto ć, a cducação, a saúde, a previdência 
social e outras. Tanto sob o ponto de vista qualitativo como quantitativo, a precaricdade tem caracterizado esses serviços, permitindo a cxistência de processo espoliativo em evolução. Como resultado, em fins da década de 80 , os favelados já constituem cerca de $8,0 \%$ da população da cidade, cnquanto $28,0 \%$ mora em corliço e parle reside cm casas precárias da periferia. Acrescentando-se os que ocupam imóveis irregulares, ou seja, em desacordo com o código de obras ou a lei de zoneamento, chega-se à cifra de $65,0 \%$ como sendo a da população de São Paulo que mora ilegalmentc e pode também submeter-se a uma das supracitadas formas espoliativas de moradia. Ao se acrescentar alguns indicadores da qualidade de vida, como a presença de scrviços básicos de água $\mathrm{c}$ esgoto, a mortalidade infantil c a educação de primeiro grau, às faixas de população de baixa renda, de até oito salários mínimos, pode-se observar a presença de pobres cm distritos e subdistritos. Ao lado de alguns, com completas redes de água c esgoto, mortalidade infantil de $8,1 \% \mathrm{c}$ de parâmetro de escolaridade de primeiro grau correspondente a mais de 100,0 , verifica-se a existência de outros com $72,0 \%$ de abastecimento de água, $11,0 \%$ de esgoto, mortalidade infantil de $75,9 \% 000$ mencionado nível de escolaridade inferior a 100,0 (Rolnik e col. ${ }^{18}, 1990$; Godoy ${ }^{7}, 1990$ ).

Diante de tais condiçōes, a densidade e a composição populacionais não poderiam deixar de sc refletir na forma de ocupação do espaço. Este, $\mathrm{cm}$ seu sentido público, evoluiu historicamente através das mudanças em seu uso e organização, da predominância inicial religiosa para a finalidade profana de nossos dias (Marx $\left.{ }^{13}, 1989\right)$. No que concerne ao aspecto de sua utilização de caráter particular, verificou-se que atualmente São Paulo é uma cidade vertical. Tal reição de verticalidade teve início nas primeiras décadas deste século, e foi progressivamente estimulado pela necessidade de divisão do trabalho e de aproveitamento dos terrenos urbanos centrais. Até a década de 40 , a verticalização objetivava precipuamente o estabclecimento de escritórios e locais de atividade profissional. A partir dessá época, deuse maior incremento ao destino residencial dos prédios de vários andares, expandindo-se pelos bairros. Multiplicaram-se assim os "edifícios de habitação colctiva" ou "de apartamentos". Dentro da multiplicidade e complexidade de interesses envolvidos no crescimento urbano, a verticalização constitui-se forma relevante de reprodução do capital, à qual se aliou nova modalidade de morar. Assim sendo, à propiedade privada dos terrenos somou-se a capacidade de tornar rentáveis árcas objeto de planos urbanísticos propostos pelo poder público (Souza ${ }^{22}$, 1989). Com isso, São Paulo assumiu a sua identidade vertical a qual, ao passar por várias disposições legislativas pretendendo disciplinar o aproveita- mento do solo na construção desses cdifícios, resultou no aspecto que alualmente domina a paisagem urbana. Este pode ser eloqüientemente definido pela expressão muito apropriada de "pesadelo paisagístico", como verdadciro retrato da desordem arquitctônica, mau-gosto acentuado, desrespcito à qualidade de vida dos habilantes, e da desenfreada e perversa cspeculação imobiliária.

Finalmente, outra das características colctivas de vida na cidade de São Paulo, reside no processo de circulaçã̃o. Os congestionamentos de trânsito constitucm fátos corriqueiros e tidos alé como normais. Contudo, têm reduzido, cada vez mais, as velocidades operacionais nas vias, especialmente as expressas, representadas pelos corredores de irradiação, $\mathrm{cm}$ scus trechos mais centrais. A inexistência de ligações suficientes entre esses corredores e a presença de trechos de conflito entre diversas modalidades de transporte, como de carga c de passagciros, constitucm outras facetas dessa problemática urbana. Com isso, o índice de mobilidade da população, definido como a relação entre o número de viagens motorizadas e o número de habitantes, decresceu de 1,54 viagem por pessoa em 1977 para $1,15 \mathrm{~cm} 1987$. A precaricdade do sistema de uransporte paulistano também resulta da situação habilacional de expansão periférica e da política de investimentos insulicientes $\mathrm{cm}$ transporte de massa e, à mancira de círculo vicioso, cstimulando o transporte individual. Estc, obviamente, acessivvel apenas a partir de determinado nível sócio-econômico.

Comprecnde-se que muilos outros aspectos colctivos poderiam ser aqui referidos c considerados, tais como, o acesso to lazer, o problema da domiciliação e da domesticação, o cmprego, subemprego e desemprego, entre outros. Claro está que não cabcriam no âmbito de simples artigo. Todavia, não se deve deixar de levar em conta, no que concerne à qualidade da vida coletiva, que todos esses aspectos agem de mancira interativa, constituindo verdadcira rede de determinantes do tipo de vida que levam os habitantes da cidade.

\section{Aspectos individuais}

Como se releriu nas páginas iniciais do presente trabalho, o estado de satisfição ou de insatisfação constitui experiência pessoal. Em sendo assim, é a opinião individual que identifica a qualidade de sua vida a quall, por sua vě, ć a resultante da influência de vários determinantes e situaçōes conseçüentes. $O$ bem-estar da pessoa, que, no di\%er da OMS, deve ser físico, mental e sociat; passa, evidentemente, pela consecução de múltiplos aspectos, que correspondem aos decerminantes da qualidade de vida individual, c que loram listados quando, parágrafos atrás, se considerou as possibilidades de sua avaliação. 
Sob o ponto de vista orgânico, os aspectos concernentes à saúde e ao estado funcional, incluem os de caráter psicológico, desde que se pretenda conceituar o "estado de doença". Este pois, como decorrente de fenômenos que se desenvolvem no organismo e que o levam a se diferenciar dos demais da mesma população, tidos como normais. Daí resulta situação que o coloca, biológica c socialmente, em posição de desvantagem $\mathrm{cm}$ relação a estes (Scadding ${ }^{20}, 1980$ ). Pode-se pois, cm relação a esse fenômeno, admitir a ocorrência de gradiente de estados subjetivos, de bem e de mal-estar individual. $E$ isso, a que atualmente se tende a dar 0 nome de "enfermidade", seria portanto concernente à situação subjetiva da pessoa afclaaii $c$ decorrente da própria conscientização de seu estado. Estc, por sua vez, determina o que se pode chamar de "anormalidade", $\mathrm{cm}$ rclação ao "papel de docnte" que o indivíduo assume na sociedade. Corresponde pois à disfunção social, afetando seu relacionamento com os demais componentes da socicdade onde vive e que, de mancira geral, compreende qualro aspectos essenciais. São eles, a irresponsabilidade pelo seu estado, a sua dependência em relação a outra instância social, médica ou não, o scu afastamento do convívio social, em grau diverso, c finalmente, a obrigação de buscar saída para essa situação (Talcott Parsons apud Almeida Filho ${ }^{1}, 1989$ ).

Diante disso, é de se admitir que tal subjetividade individual, resultante de estado particular, pode ou não vir a ser conscientizada pela pessoa. Para o primeiro caso, já se referiu no parágrafo anterior as suas principais características de disfunção social. No entanto, a sociedade atual tende cada vez mais a induzir novas necessidades, para cuja satisfação, a qualidade de vida individual pode chegar a ser afclada, $\mathrm{cm}$ maior ou menor grau, e freqüentemente sem que a pessoa se conscientize disso. Além de todos os aspectos colelivos anteriormente mencionados, muitos outros existem e são constantemente criados nesse sentido. Para se ater apenas a alguns deles, há que se dizer que o meio urbano da cidade de São Paulo tende a comprometer seriamente a identidade, o relacionamento, a privacidade, o lazer, a renda, a posição social e o significado da própria vida. De mancira geral, tais aspectos constituem-se em problemas que, ao afetarem a qualidade de vida, são de difícil solução, uma vez que se apresentim como consecuüentes da cvolução e do "progresso" das socicdades modernas (Laucr ${ }^{11}, 1978$; Spirn ${ }^{23}, 1984$ ).

A problemática da restrição do espaço urbano afcua não apenas os indivíduos de baixa renda, mas também aqueles dotados de maior poder aguisitivo. Assim, por exemplo, com freqüência os moradores em prédios de apartamentos dispóem de clevadas condições de conforto, às ve\%es ao nível de hotelaria, como nos chamados "flats". Não obstante, se bem que os problemas relativos à qualidade de vida para os menos abonados tenham pouca probabilidade de ocorrerem em lais siluações, podem surgir outros tipos de comprometimentos. O aspecto coletivo desses lipos de habitação tende a descaracterizar, cada vez mais, o que se pode entender como ambiente de moradial. Eis qque, $\mathrm{cm}$ tais formas de residência, sacrilica-se as sensaçôes de liberdade, de privacidade e de individualidade, que cada ser humano necessita c almeja para si c scus familiares. Acresce a monotonia elcvada a grau extremo, a ausência de diversificações paisagísticas e, às vezes, mesmo de paisalgem que mereça csse nome, e a convivência obrigatória com vizinhança não previamente escolhida. Diante de tais feições, consciente ou inconscientemente, o morador de apartamento transforma a que deveria ser sua residência, mais em alojamento do que em moradia propriamente dita (Foraltini 6 , 1980).

A concentração urbana representa o meio ideal para o desenvolvimento da competilividade em todos os setores. A televisão, atingindo metade ou mais da população brasileira, tem na cidade os seus maiores índices de audiência. Exerce papel relevante na aglutinação de pessoas, doutrinando-as, à maneira de gigantesca catequese, para o consumo de inúmeros produtos, nem sempre propiciadores de melhores niveis de qualidade de vida. A publicidade desenfreada, cuja única finalidade reside no estímulo ao consumo, muitas vezes age como determinante de poluição visual, sonora c ambiental, inundando a população com os mais variados meios de propaganda. A imprensa quotidiana anuncia a venda, desde necessidades indispensáveis à vida, como o ar, a luz, a paisagem, até órgãos humanos para transplante. Diante de tal ambiente, consciente ou inconscientemente hostil, os indivíduos tendem a optar pela solução da fuga. Esta, forçosamente temporária, manifesta-se pelo êxodo que observam $\mathrm{cm}$ São Paulo, por ocasião dos lins de semana e de leriados prolongados. À mancira de verdadeira compulsão colctiva, ocorre nessas ocasiões a fuga da população urbana, o que pouco resolve, a mais das veres levando para as estradas e outras cidades a sua própria problemálica para, em seguida, voltar com cla. Porém, como decorrência, dá-se a proliferação de novo artigo de consumo, consubstanciado pela indústria do turismo que, à scmelhança da publicidade, propicia o surgimento de muitas calegorias de profissionais que a cla se dedicam (Krippendorl ${ }^{10}, 1989$ ). Como se pode ver, sĩo inúmeros os aspectos individuais que determinam a qual idade de vida no meio urbano. O caráter subjelivo de que se revestem, sujeita o seu estudo a avaliaçôes abstratas, nem sempre precisas e viáveis. De qualquer forma, constitui-se em desalio para 
pesquisas altamente promissoras, tendo a cidade de São Paulo como cenário.

\section{Considerações finais}

Admitem-se, de modo consensual, os inconvenientes do meio urbano para a qualidade de vida do homem. Consubstanciam-se $\mathrm{cm}$ seus aspectos poluídos, desgastantes, violentos, estressantes, socialmente isolantes e de difícil solução. Conhece-se razoavelmente bem a natureza dos problemas desse ambiente, mas o mesmo não se pode afirmar a respeito da consciência de que as cidades são também das maiores contribuintes às ameaças ambientais do plancta, como um todo. A aceleração e o incremento desmesurado do processo de urbanização, com a concentração cada vez maior da população humana, além de detcriorarthe a qualidade de vida, tende a exaurir, $\mathrm{cm}$ ritmo nunca visto, os recursos da biosfera.

Diante desse alarme, verifica-se o inicio de reação a esse estado de coisas, com o surgimento de consciência individual e colctiva. Daí a recente ênfase no desenvolvimento do que se conhece pelo nome de "ecologia urbana", como área de estudo c de planejamento. Nos países $\mathrm{cm}$ que essa orientação encontra-se em progresso, parle-se do princípio de ser possível a existência de cidade ccologicamente sadia ("ecocity"), ou seja, cm equilíbrio com o ambiente natural e com a sociedade que a habia (Bruning $^{2}$, 1991). Assim, não haveria necessariamente incompatibilidade entre a instalação de centro urbano e a qualidade de vida do homem. A questão estaria principalmente na maneira de instalát-lo, de lorma a oferecer a scus habitantes, cultura, educalção, saúde, lazer, interação social, oportunidades de trabalho e distribuição elíciente e justa de serviços e benefícios. Tais objetivos constituem, atualmente, campo de intensos estudos, nas sociedades assim dilas desenvolvidas, ou seja, do Primeiro Mundo. Quanto à terceiromundista cidade de São Paulo, os imensos problemas com que se vê a braços, desaliam os estudos destinados a encontrar soluções adequadas à qualidade de vida de seus habitanles. É de se esperar que as luturas geraçõos de paulistanos se engajem nesse objetivo e encontrem meios de propiciar melhor vida para si e seus descendentes.

As folografias (Figuras 1 a 11) que são apresentadas a seguir destinam-se a ilustrar alguns dos aspectos de São Paulo, em relação à problemálica tratada no presente artigo.

FORATTINI, O.P. [Quality of life in an urban environment. S. Paulo city, Brazil]. Rev. Saúde públ., S. Paulo, 25: $75-86,1991$. The coneept of the quality of life is presented: its main aspects and the possibilities of this assessment and measurement are presented. Community and individual features are described and related to causal factors. S. Paulo city, Brazil, is seen to be an urban environment with quality of life problems on which some considerations are offered.

Keywords: Quality of life. Urban population.

\section{Referências Bibliográficas}

1. ALMIIDA FILIIO, N. de. İpidemiologia sem números. Rio de Janciro, Ed. Campus, 1989.

2. BRUNLYG, N. Urban ccology. Buzzworm, 3(1): 18, 1991.

3. COLMBRA, S. de A.A. O outro lado do meio ambiente. São Paulo, CEIT:SB/ASCL'ILSB, 1985.

4. DAM, F.S.A.M. van; SOMERS, R.; BELCK-COUZIN, A.L. van. Quality of life: some theoretical issues. J. clin. Pharmacol, 21: 1665-85,1981.

5. DU TOIT, B.M. People on move. Rural-urban migration with special reference to third world: theoretical and empirical perspectives. Hum. Org. 49:305-19, 1990.

6. FORATTLII, O.P. Epidemiologia geral. São Paulo, Livr. Ed. Artes Médicas, 1980.

7. GODOY, I. A megalópole dos barracos c contiços. Jornal da'Tarde, São Paulo, 29 nov.,1990. p. 36.

8. IIÖRNQUISI', J.O. The concept of quality of life. Scand. $J$. soc. Med., 10: 57-61, 1982.

9. IIÖRVQUISI, J.O. Quality of life: concept and assessment. Scand. J. soc. Med. 18: 69-79, 1990.

10. KRIPPENDORF, J. Suciologia do turismo. Rio de Janeiro, Ld. Civilizatção Brasilcira, 1989.

11. LALER, R.H. Social problems and the quality of life. Dubuque, Iowa, Wnr. C. Brown Co. Publ, 1978.

12. LOPIS, J.B. \& GOTTSCIMLK, A. Recessão, família e po. brezai: a década mais do que perdida. S. Paulo Perspect., 4: $100-9,1990$.

13. MARX, M. Nosso chão: do sagrado ao profano. São Paulo, I:d. USP, 1989

14. PAPAGFOROIOU, J.C. Quality of life indicators. Int.J.environ. Silud., 9: 177-86, 1976.

15. RIBIS Jill.IIO, N.G. Contribuição ao estudo da evolução urbana do Brasil. São Paulo, Pioncira Ld./ Ed.USP, 1968.

16. RIGIII, R. O processo de urbanização e o desenvolvimento industrial no Estado de São Paulo. In: Bruna, G.C., org. Questōes de organização do espaço regional. São Paulo, l.jvr. Nobel/Ed. USP, 1983. p. 43-92.

17. ROCIIA, S. La pobreza en el Brasil en los años 80 . Rev. occid. Tijuana, Baja California N, 7: 361-79, 1990.

18. ROLNIK, R.; KOW ARIK, L.; SOMLKII, N., cds. Säo Paulo: crise e mudança. São Paulo, Prefeitura de São Paulo/ Brasiliense, 1990.

19. RONCA, J.L.C. Metropolização e desenvolvimento do 13rasil, In: Bruna, G.C., org. Questöes de organização do espaço regunal. Sĩo Paulo, Livr. Nobcl/Ld.LSP. 1983 . p. $119-50$.

20. SCANDDING, S.G. The concepls of discase: a respouse. Psychol.Med., 10: -725-7, 1980.

21. SINGI:R, P’. Desenvolvinento económico e evoluşäo urbana. Süo Paulo, Ld. Nacional/lid. LSP, 1968.

22. SOLZA, M.A.A de. A identidade da metróple. A vertica. lização em São Paulo. São Paulo, Departamento de Geografia da laculdade de Filosolia, Letras e Ciências IIumanas da LSP', 1989.

23. SIIRN, A.W. The yranile garden. Urban nature and human design. New York, Basic Books Inc. Publ, 1984.

Rccobido para publicação em 26/03/1991 
Figuras 1 a 11 . Alguns aspectos do comprometimento da qualidade de vida no meio urbano da cidade de São Paulo.

\section{Habitabilidade:}

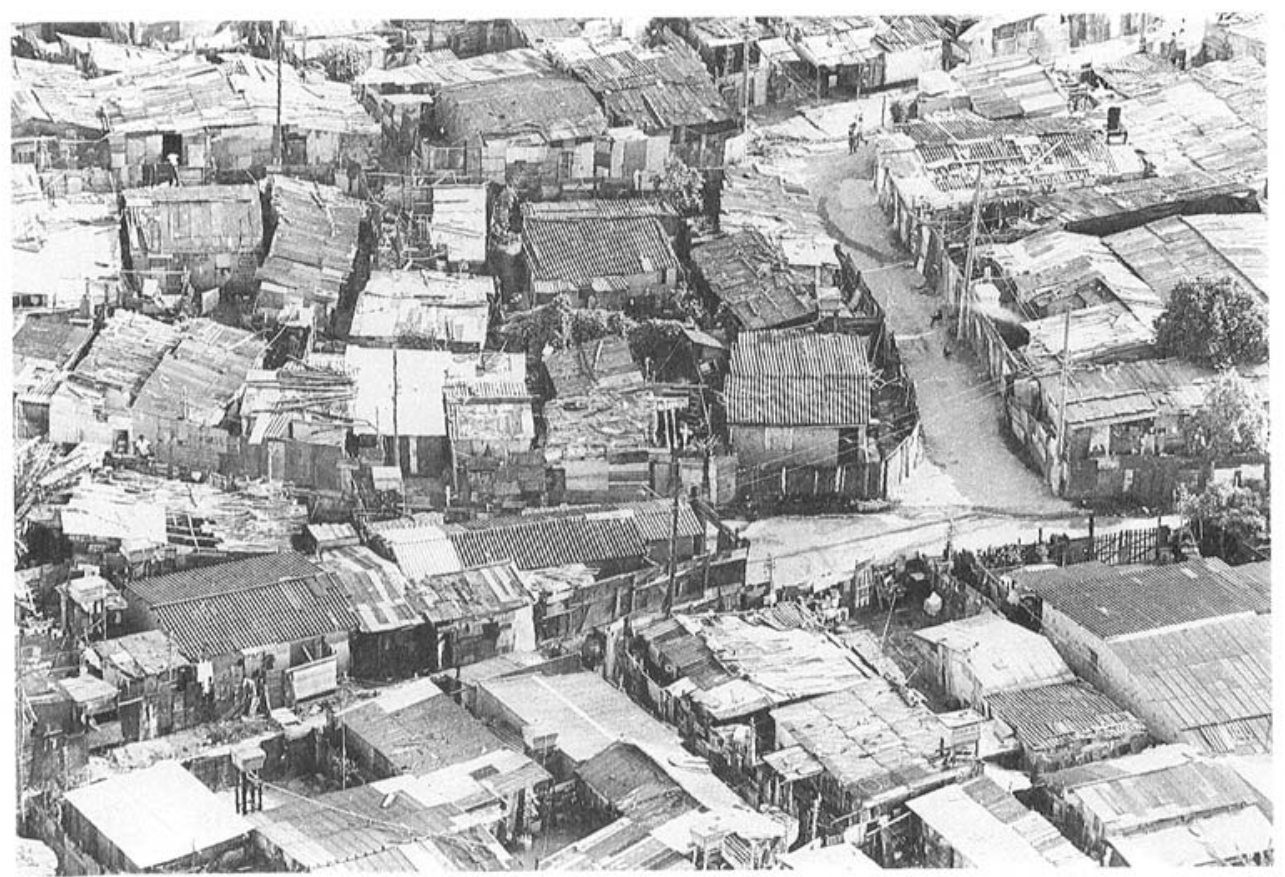

Figura 1 . Favela, como detertoraçáo "a priorı" da morada

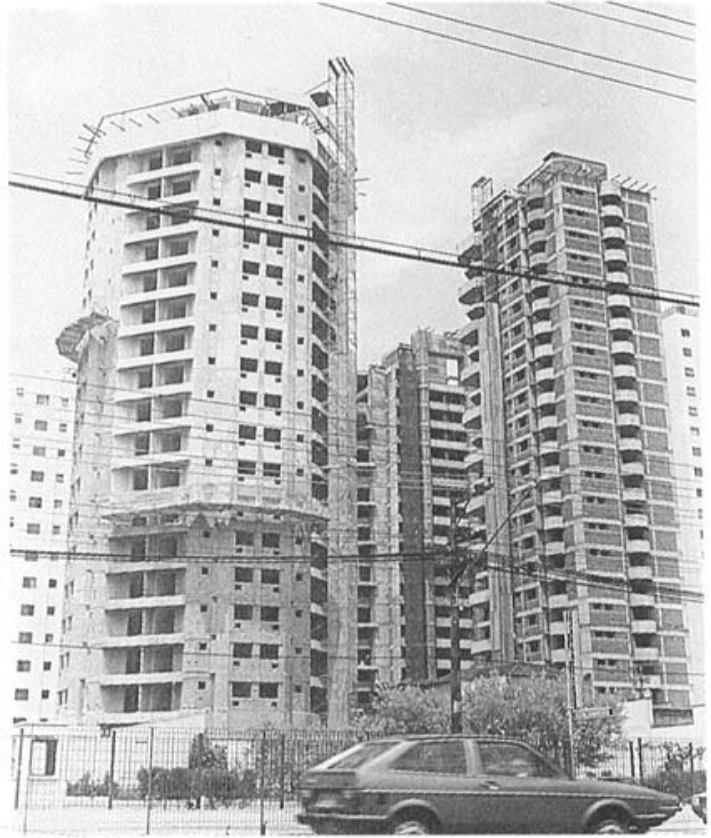

Figura 2. Frédios de apartamuntos, como exumpius de continamento e monotona 


\section{Paisagem:}

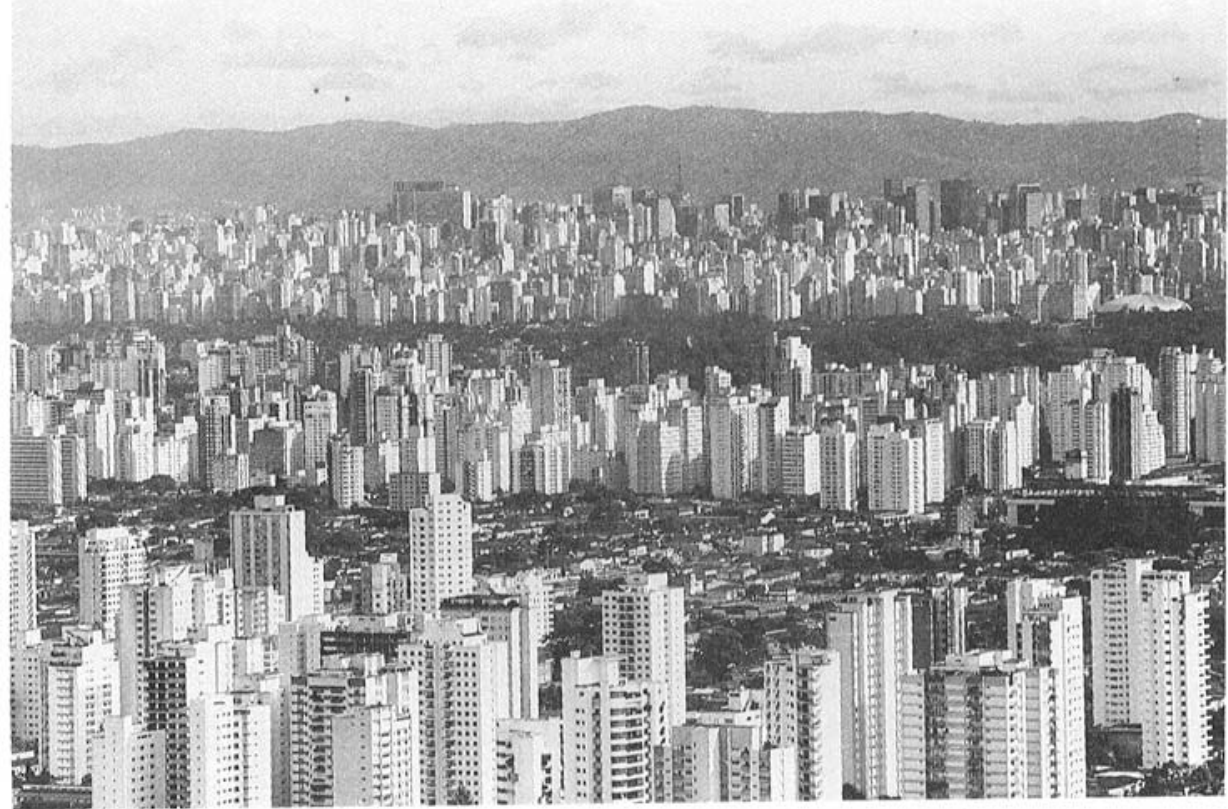

Figura 3 . Verticalıdade

Foto Luludi/Agência Estado

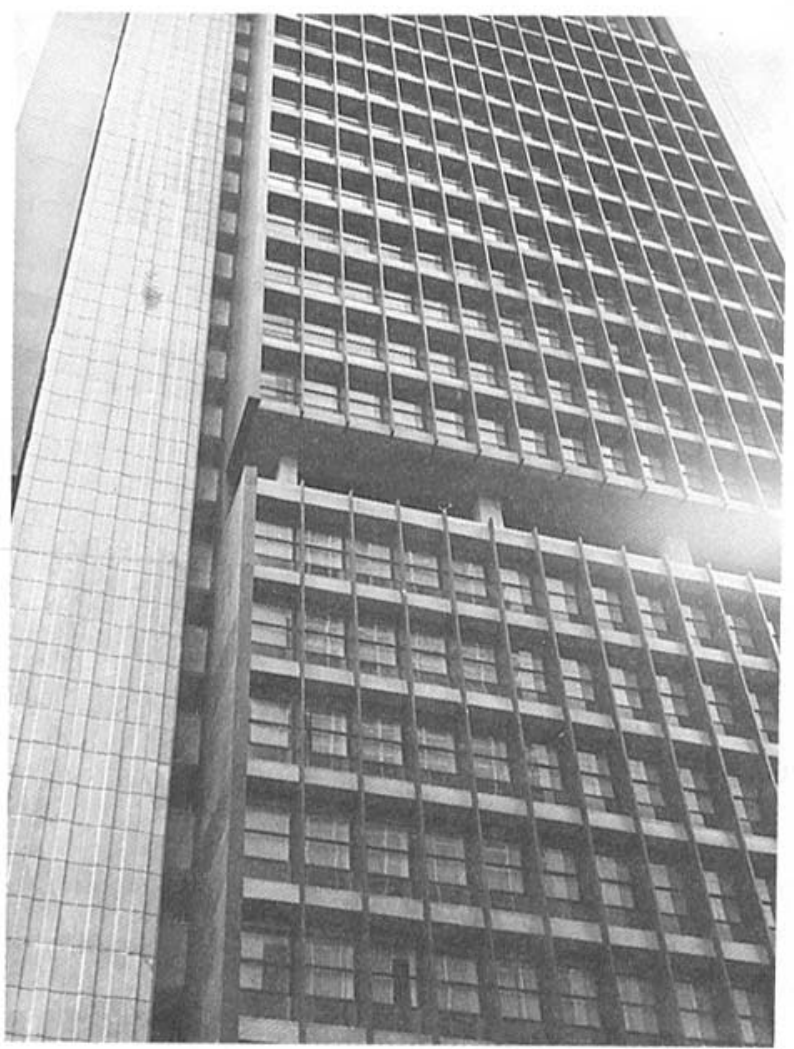

Figura 4 . Uniformidade e extrema ausência de diversıficação 


\section{Poluição visual:}

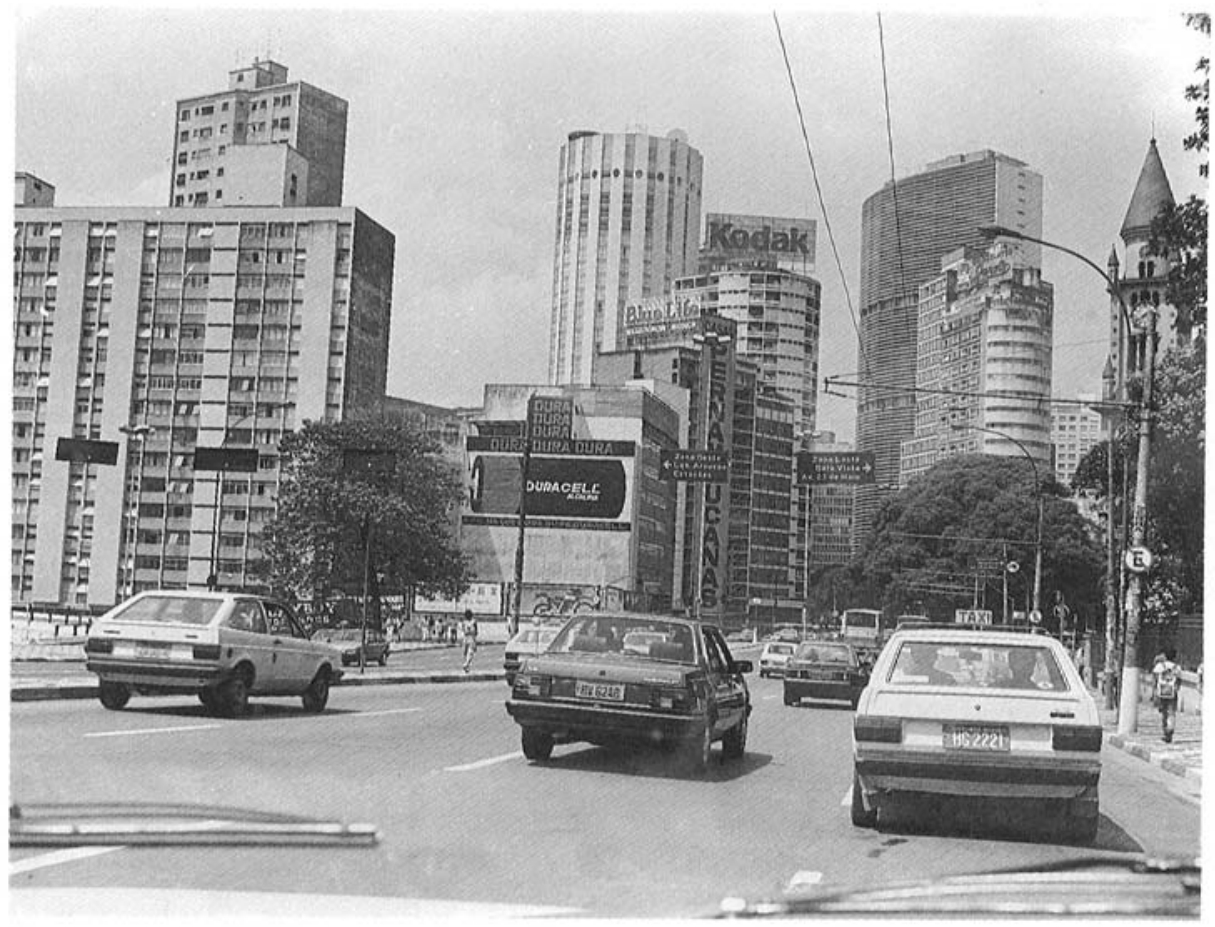

Figura 5 Desarmona e ocupaçāo desordenada do espaço

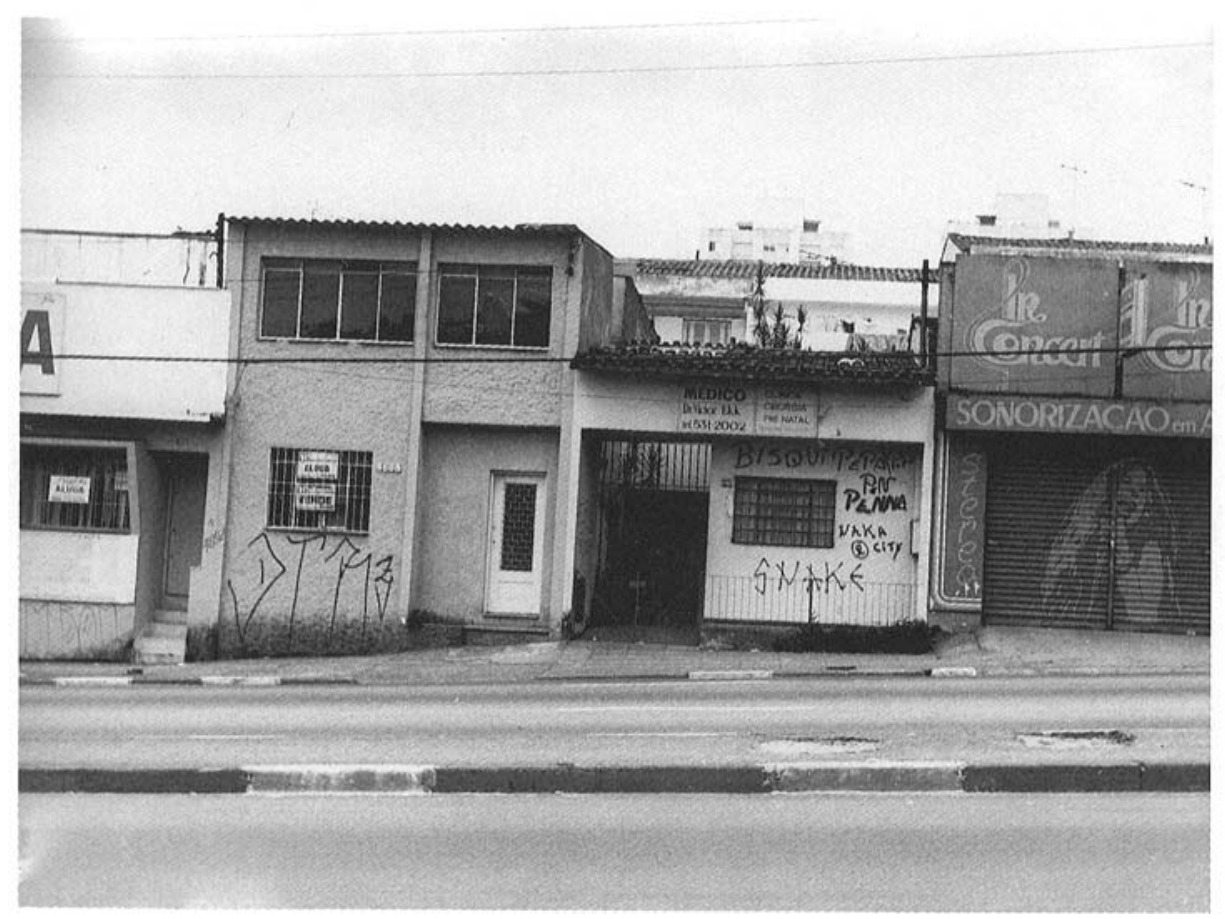

Figura 6 Aproveitamento inadequado do espaço e plchaçôes anónimas 


\section{Circulação:}
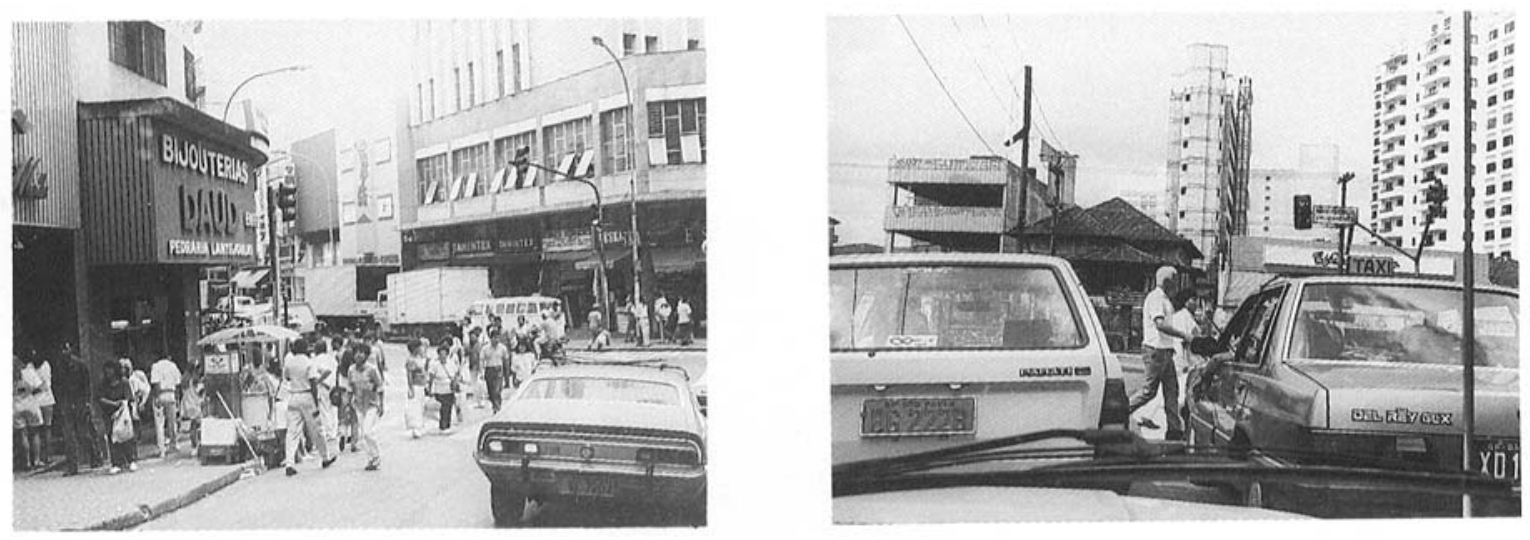

Figuras 7 e 8 . Pedestres e veículos na disputa do espaço público.

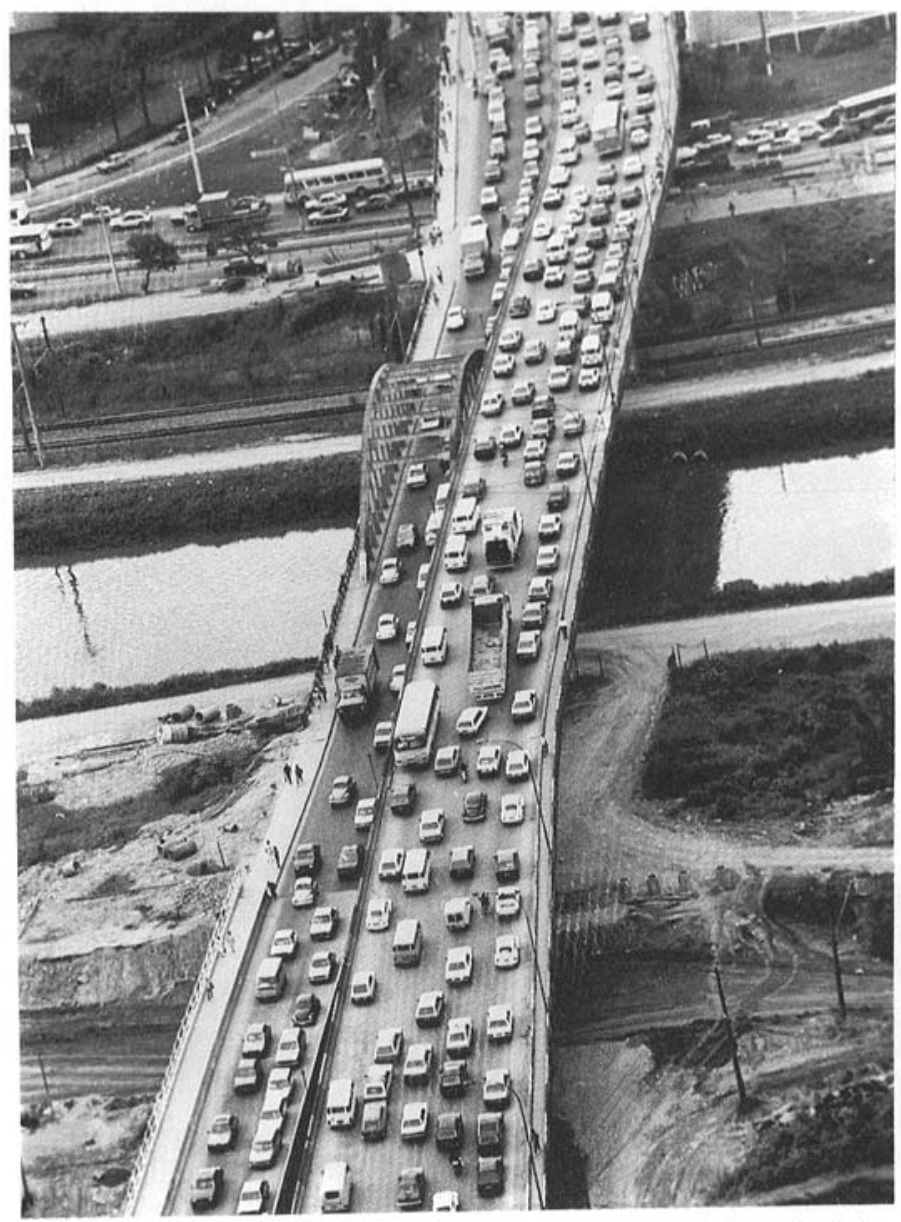

Foto F, Santos/Ag. Folhas

Figura 9 . Congestionamento do trânsito de veículos 


\section{Comunicação e consumo:}

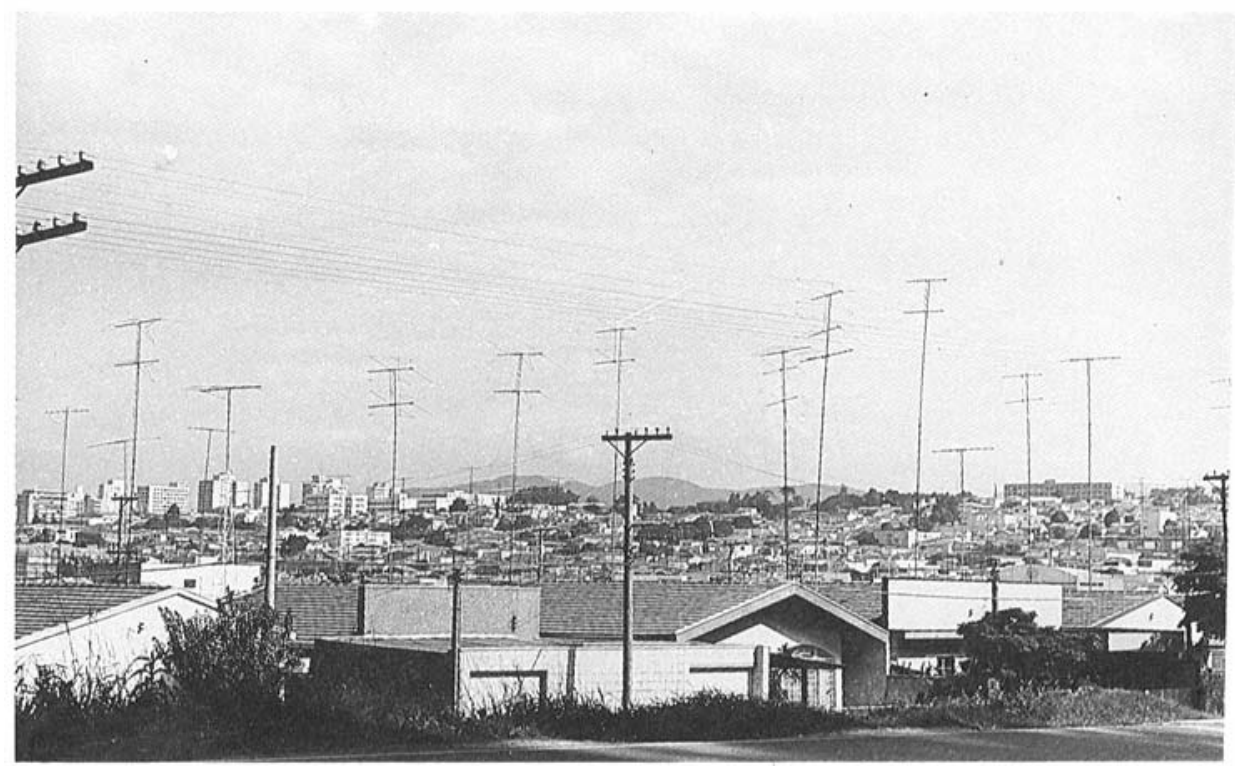

Figura 10 Televisiio

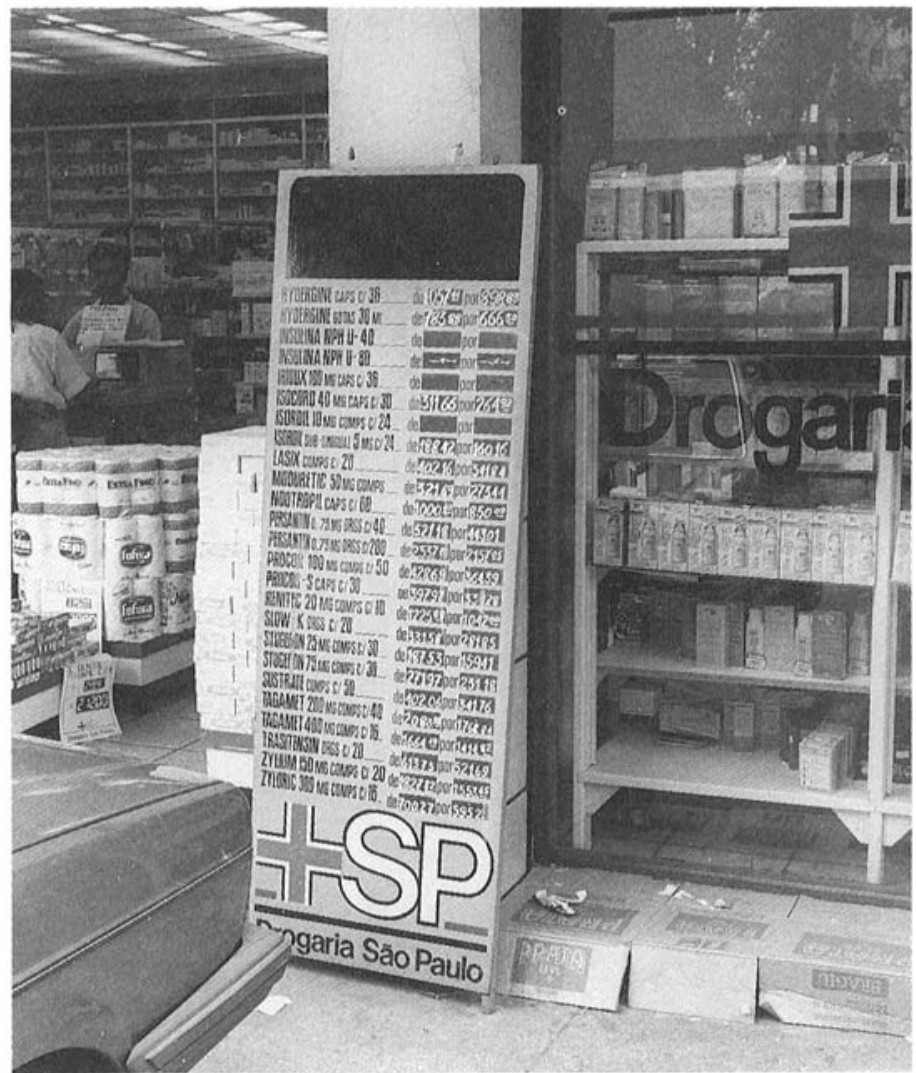

Figura 11 Comércio e medicação. 